\title{
Kesiagaan Perpustakaan dalam Menghadapi Bencana di Perpustakaan Universitas Sebelas Maret Surakarta
}

\author{
Haryanto* \\ email: haryanto12370@gmail.com
}

\begin{abstract}
This research aims to find out the preparedness of libraries in facing disasters caused either human or natural factors. Disasters caused human factors are fire, theft and various kinds of acts of vandalism, while disasters caused by natural factors are earthquakes, floods and the threat of devastating animal collection.

The research method used in the study is qualitative field research. Data were obtained through observation and note-taking, as well as participation in the activities.

Disaster preparedness activities were conducted in stages, prevention, response, reaction and recovery. These activities included filling up visit book, CCTV cameras, availability of portable fire extinguisher and SOP (standard operating procedure) that put priority in securing the collection, repair, creation of data backup and recovery, media transfer, procurement of collection and extensive simulation handling of fire and other emergency conditions.
\end{abstract}

Keyword: Disaster management, preservation, Collection

*) Pustakawan UPT Perpustakaan Univ. Sebelas Maret Surakarta

\section{A. PENDAHULUAN}

Dalam The Role of Libraries and Librarians in Organising Digital Information Peter Ingwersen (1999:11-15) mengatakan bahwa Perpustakaan Perguruan Tinggi telah menjadi "mesin" utama untuk penyimpanan, pengorganisasian, pusat akses, distribusi dan penggunaan informasi yang berkualitas. Hal ini berarti bahwa Perpustakaan Perguruan Tinggi telah dan akan terus memainkan peran yang sangat penting dan utama sebagai media repository dalam kehidupan suatu perguruan tinggi. Bryan Heidord P (2011:663) mengemukakan perpustakaan Perguruan Tinggi mempunyai tujuan untuk mengumpulkan dan menyebarkan informasi untuk mendukung tujuan dari institusi serta pendidikan dan penelitian. Ridwan Siregar (2008:7) juga mengemukakan dengan berbagai fungsi tersebut menjadikan Perpustakaan Perguruan tinggi sangat diperlukan untuk riset, pengajaran dan pembelajaran. Maidabino dan Zainab (2011:16) juga mengemukakan, seba-gai media repository penunjang riset perpustakaan perguruan tinggi mempunyai tugas utama menyediakan sumber informasi baik tercetak maupun digital. Perpustakaan Perguruan Tinggi harus berkualitas karena sistem belajar mandiri di perguruan tinggi menuntut mahasiswa membutuhkan berbagai sumber informasi yang relevan sehingga perpustakaan harus memfasilitasi kebutuhan tersebut.

Dalam pengelolaannya, sering-kali perpustakaan perguruan tinggi hanya terfokus pada kegiatan rutin seperti layanan peminjaman, penelusuran informasi, dan manajemen informasi. Padahal selain kegiatan rutin yang bersifat layanan tersebut berbagai faktor bencana baik yang ditimbulkan oleh manusia maupun alam mengancam keberadaan dan kelangsungan sumber-sumber informasi tersebut. Alegbeleye dalam Abdul Wahab Olan Rewaju Issa(2016) mengingatkan bahwa bencana yang mengancam perpustakaan adalah sebagai suatu peristiwa yang mengakibatkan penghapusan tiba-tiba catatan dan dokumen dari aksesibilitas dan penggunaan. Dinyatakan lebih lanjut bahwa bencana dapat dianggap sebagai suatu kejadian yang sementara atau permanen membuat informasi yang terkandung 
dalam dokumen terganggu atau tidak dapat diakses. Bencana tersebut tidak dapat dihindari tetapi dapat diprediksi, diantisipasi dan diminimalkan oleh manusia. Bencana yang di timbulkan oleh alam dan dapat mengancam koleksi perpustakaan diantaranya berupa gempa bumi, banjir, gunung meletus, kebakaran, serangga, hewan pengerat, dan jamur. Sedangkan bencana yang ditimbulkan oleh manusia dan mengancam koleksi perpustakaan yaitu kebakaran, pencurian, dan berbagai jenis tindak vandalisme.

UPT Perpustakaan Universitas Sebelas Maret Surakarta sampai saat ini masih menemui tindak vandalisme atau perusakan koleksi terhadap buku, skripsi, tesis , jurnal serta laporan penelitian. Bentuk kerusakan tersebut di antaranya hilangnya beberapa halaman, corat coret pada buku, jilidan yang rusak, halamanhalaman terlipat, halaman berjamur karena lembab, atau hilangnya koleksi setelah diadakan stok opname. Kerusakan dan kehilangan koleksi tersebut tentu sangat disayangkan karena menggangu nilai kelestarian koleksi. Koleksi yang rusak atau hilang tentu tidak dapat lagi digunakan untuk memenuhi kebutuhan informasi. Akibat lain adalah menghilangkan aspek dokumentasi. Padahal koleksi karya ilmiah, prosiding dan lain-lain, sebagai literatur kelabu yang merupakan koleksi terbatas. Apabila koleksi itu mengalami kerusakan atau hilang, maka akan mengakibatkan hilangnya sumber informasi yang penting.

Berbagai bentuk bencana di atas dapat mengancam kelestarian koleksi. Untuk itu diperlukan upaya kesiagaan dalam menghadapi bencana. Baik bencana yang di timbulkan oleh alam maupun manusia. Dalam Kamus Besar Bahasa Indonesia (2012:1297) kesiagaan berarti kesiapan. Kemudian, bencana dalam konteks ilmu perpustakaan menurut Matthews dan Feather (2003:31) adalah segala bentuk kejadian yang mengancam keamanan dari manusia dan atau membahayakan atau mengakibatkan kerusakan pada bangunan, koleksi, isi, fasilitas dan layanan. Jadi kesiagaan dalam menghadapi bencana di perpustakaan yaitu kesiapan perpustakaan dalam menghadapi bencana yang sewaktuwaktu dapat terjadi. Dengan adanya kesiapan diharapkan meminimalkan kerusakan dan mencegah kerusakan koleksi.
Berdasarkan hal tersebut di atas maka perlu dilakukan kajian kesiapan dalam menghadapi berbagai bencana di perpustakaan untuk menjaga keutuhan dan kelestarian koleksi sehingga dapat dipergunakan untuk waktu yang lama. Koleksi yang berkualitas, dengan pengelolaan yang baik, kiranya kurang bermakna tanpa adanya usaha pencegahan bencana. Bencana akan mengancam keutuhan koleksi dan sarana prasarana perpustakaan. Apabila koleksi rusak maka akan kehilangan nilai kemanfaatannya

\section{B. TINJAUAN PUSTAKA LANDASAN TEORI}

Kata kesiagaan dalam Kamus Besar Bahasa Indonesia (2012:1297) berarti kesiapan, yaitu kesiapan menghadapi bencana yang merupakan kegiatan persiapan yang diupayakan untuk mengurangi kerusakan akibat bencana. Menurut Matthews dan Feather (2003:31) pengertian bencana dalam konteks ilmu perpustakaan adalah segala bentuk kejadian yang mengancam keamanan dari manusia dan atau membahayakan atau mengakibatkan kerusakan pada bangunan, koleksi, isi, fasilitas dan layanan. Sedangkan Ros Harvey (1993:123) mengemukakan elemen-elemen dari rencana kesiagaan menghadapi bencana yang meliputi pencegahan, tanggapan, reaksi, dan pemulihan.

Menurut Dureau dan Clements ( 1990:13) Bahan pustaka yang memiliki karakteristik perbedaan waktu, peradaban, dan bentuk merupakan ungkapan kehidupan intelektual dan budaya pada suatu masa dan tempat tertentu. Tujuan dan fungsi perpustakaan adalah mengumpulkan, menata, melestarikan dan menyediakan bahan pustaka dalam berbagai bentuk, semua bahan yang mempunyai kemampuan memuat atau merekam pengetahuan dan pikiran manusia. Oleh karena itu semua perpustakaan memiliki tugas melestarikan koleksinya secara terus-menerus sebagai bagian dari pelestarian bahan pustaka. Pustakawan dan petugas perpustakaan juga bertugas membangun kesadaran untuk melestarikan dan memelihara koleksinya. Meskipun bahan pustaka memiliki tujuan untuk digunakan, namun Dureau dan Clements (1990:18) menyebutkan bahwa di antara tugas pustakawan dan petugas perpustakaan adalah: 
1. menjamin bahwa bahan pustaka digunakan sedemikian rupa sehingga tidak rusak.

2. membatasi pemakaian bahan yang langka dan berharga bagi pemustaka yang memerlukan bahan aslinya.

Definisi pelestarian menurut International Federation Library Association and Institution (IFLA) mencakup semua aspek usaha melestarikan bahan pustaka, keuangan, ketenagaan, metode dan teknik serta penyimpanannya. Jadi, kesiagaan menghadapi bencana merupakan bagian dari pelestarian bahan pustaka (Preservasi).

Dalam rangka mengantisipasi bencana diperlukan persiapan tindakan penyelamatan sebagai usaha pertama yang dilakukan dalam suatu institusi apabila sewaktu-waktu terjadi suatu bencana. Bencana yang dapat membahayakan koleksi dan sarana prasarana perpustakaan dapat disebabkan faktor manusia seperti pencurian, kurangnya pengamanan, pembakaran dan lain sebagainya. Bencana ini dapat juga diakibatkan oleh alam seperti gempa bumi, gunung meletus, dan badai dengan skala yang bervariasi. Dureau dan Clements (1990:35) mengatakan bahwa sebuah perencanaan terhadap bencana merupakan elemen yang penting dalam melakukan tindakan pencegahan dalam upaya pelestarian. Inti dari rencana bencana meliputi pengetahuan tentang bangunan, identifikasi koleksi, pencegahan bencana, teknik pemulihan, ketersediaan bantuan dari luar, serta keberadaan suatu struktur pengambilan keputusan. Namun yang berperan sangat penting dalam kesiagaan menghadapi bencana adalah unsur manusia (pustakawan dan petugas perpustakaan lain).

Adapun elemen-elemen dari rencana kesiagaan menghadapi bencana menurut Ros Harvey (1993:123), meliputi: pencegahan, tanggapan, reaksi dan pemulihan.

Pada tahap pertama yaitu tahap pencegahan, tahap pencegahan ini adalah untuk mengidentifikasi penyebab bencana dan untuk memperkecil risiko yang dihadapi oleh perpustakaan itu sendiri, yaitu berbagai peralatan terkait safety tools. Kesiagaan ini mencakup berbagai kegiatan prosedur atau peralatan yang disiapkan untuk mencegah terjadinya bencana, meliputi:

1. pemeriksaan bangunan.

2. pemeriksaan perlindungan terhadap kebakaran dan alat pendeteksi, juga alat pendeteksi pencurian.

3. pembuatan back-up atau salinan duplikat termasuk katalognya.

4. mengasuransikan, premi akan berkurang bila tindakan pencegahan ditingkatkan.

Tahap kedua yaitu tahap tanggapan, yaitu berbagai kegiatan yang diterapkan sebelum keadaan darurat karena bencana terjadi. Tahapan ini meliputi:

1. penetapan dan pelatihan staf.

2. identifikasi koleksi dan memberikan prioritas utama pada koleksi langka.

3. pemeliharaan peralatan yang digunakan untuk penyelamatan koleksi.

4. mendaftar nama dan lembaga penting yang harus dihubungi jika terjadi bencana.

5. membuat prosedur rencana penanggulangan bencana.

Tahap ketiga yaitu tahap reaksi, merupakan aktivitas yang dilakukan ketika bencana sudah terjadi. Tahap ini berhubungan langsung dengan arah penentuan kebijakan, yang meliputi: menentukan langkah prosedur yang dilakukan ketika terjadi bencana, memastikan lokasi bencana aman dimasuki, dan memindahkan materi yang rusak.

Tahap keempat yaitu tahap pemulihan, yang mencakup kegiatan jangka panjang untuk memulihkan kembali sistem yang lumpuh atau terganggu selama bencana. Tahap ini meliputi penetapan dan pelaksanaan program memperbaiki lokasi bencana dan materi yang rusak, mengambil teknik penyelamatan terhadap koleksi, serta menganalisis bencana dan perbaikan rencana bencana.

\section{METODE PENELITIAN}

Kajian ilmiah ini merupakan penelitian lapangan atau field research yang bersifat kualitatif. Dalam pelaksanaan penelitian, peneliti menyatu dengan situasi yang diteliti dan menekankan pada pentingnya kedekatan dengan orang-orang dan situasi penelitian agar peneliti memperoleh pemahaman jelas tentang realitas dan kondisi kehidupan nyata. (Lexy J. Moleong (2007:6). Pengumpulan data dalam peroleh dengan langkah-langkah melalui observasi yaitu mencatat, mengamati serta berperan serta dalam kegiatan aktivitas di dalamnya, selain itu juga dilakukan wawancara. 


\section{HASIL DAN PEMBAHASAN}

Kesiagaan menghadapi bencana sendiri merupakan kegiatan berulangkali yang diupayakan agar mengurangi kerusakan akibat bencana. Elemen-elemen dari rencana kesiagaan menghadapi bencana meliputi: pencegahan, tanggapan, reaksi, dan pemulihan. Berikut merupakan hasil interpretasi yang peneliti lakukan:

\section{Tahap Pencegahan}

Petugas Perpustakaan UPT Perpustakaan UNS melakukan tindakan pencegahan dengan mewajibkan pengunjung untuk mengisi buku kunjungan dan meminta identitas pengunjung yang berasal dari luar kampus. Selain dengan mengaktifkan buku pengunjung perpustakaan juga sebaiknya memasang kamera CCTV.

Kamera CCTV selain mengawasi seluruh ruang, terdapat satu kamera khusus yang diarahkan kepada pengunjung yang masuk, sehingga rekaman pengunjung akan jelas terlihat dan tersimpan dalam kurun waktu tertentu dalam harddisk data rekam unit kamera perpustakaan. Hal ini merupakan suatu bentuk pencegahan dengan mendokumentasi visual setiap pengunjung yang datang. Selain itu juga bertujuan agar pengunjung perpustakaan mengetahui bahwa gambar diri pengunjung tersebut direkam sehingga menimbulkan rasa takut untuk berbuat yang merugikan perpustakaan dan orang lain.

Pada tahap pencegahan yang juga tidak kalah penting adalah pemeriksaan perlindungan terhadap kebakaran berupa tabung pemadam portable merupakan suatu kebutuhan untuk pencegahan kebakaran. Alat tersebut diletakkan di tempat yang strategis dimana petugas dapat dengan mudah menggunakannnya misalnya pojok di bawah tangga. Selain itu, perlu juga pengumuman larangan untuk merokok di dalam perpustakaan. Kebakaran merupakan bencana yang paling potensial terjadi di mana saja. Selain itu, bencana kebakaran akan mengakibatkan kerusakan pada koleksi yang sangat parah bila dibandingkan dengan bentuk bencana lainnya. Sekecil apapun api dapat menimbulkan kerugian.
Oleh karena itu, mencegah kebakaran adalah suatu hal yang penting dibandingkan dengan usaha memadamkannya. Selain itu bentuk usaha pencegahan dengan cara mengadakan sosialisasi kepada mahasiswa tentang tata penggunaan koleksi yang baik dan benar dalam forum Osmaru atau setiap hari Perpustakaan memberikan layanan pendidikan pemakai pada kelompokkelompok kecil pemustaka yang ingin mendayagunakan berbagai fasilitas yang ada di UPT Perpustakaan UNS.

\section{Tahap Tanggapan}

Tahap yang kedua yaitu tahap tanggapan, merupakan berbagai kegiatan atau program dan sistem yang diterapkan sebelum keadaan darurat terjadi. Usaha tanggapan yang dilaksanakan yaitu sudah tersedianya SOP (Standart Operating Procesure) berupa urutan prioritas koleksi dalam penyelamatan ketika terjadi bencana berupa prosedur mutu, lainnnya yaitu mengikutsertakan dalam berbagai pelatihan tentang preservasi dan tanggap bencana seperti yang pernah di ikuti yaitu Workshop emergency response and recovery team for record: preservation system yang diselenggarakan oleh Perpusnas di Yogyakarta pada 28 - 30 November 2011. Selain itu kerjasama dengan pihak terkait juga dilakukan seperti pemadam kebakaran untuk simulai seandainya terjadi kebakaran. Kerjasama ini dilakukan dengan Pusat Arsip Nasional untuk pelatihan preservasi. Berbagai persiapan tersebut dipersiapkan perpustakaan sebagai upaya persiapan jika terjadi bencana di perpustakaan.

\section{Tahap Reaksi}

Tahap yang ketiga yaitu tahap reaksi, merupakan aktivitas yang dilakukan jika benar-benar sudah terjadi bencana. Bencana yang terjadi sebagian besar berupa tindak vandalisme yakni mengambil beberapa lembar dengan cara disilet, mencorat coret buku, menandai dengan stabilo, membuat buku menjadi basah (sering terjadi ketika musim hujan). Sedangkan yang diakibatkan faktor alam misalnya tumpukan skripsi, tesis yang ada 
di gudang dan belum diproses. Bahan pustaka tersebut rusak karena terlalu lembab kemudian berjamur atau dirusak hewan pengerat. Selain beberapa hal kerusakan koleksi diatas yang paling sering ditemui adalah kerusakan jilidan, sehingga halaman menjadi tidak urut dan bentuk buku kusut. Hal ini sering terjadi karena kualitas jilidan buku-buku sekarang sangat buruk, sehingga baru dipakai beberapa bulan saja jilidan sudah hancur. Tahap reaksi ini Perpustakaan FH UNS mengambil tindakan langsung dalam perbaikan jika tingkat ringan seperti penjilidan dan lain-lain. Untuk buku yang hilang beberapa halaman dilakukan perbaikan penambahan isi yang hilang dengan fotokopi dari koleksi lain kemudian disatukan dan di jilid ulang. Namun jika kerusakan koleksi berat bisa dilaksanakan dengan alih media dengan scanning koleksi. Untuk penanganan koleksi yang basah, bagian preservasi mempunyai tempat pengeringan sistem dingin sehingga koleksi yang basah dapat di pulihkan tanpa merusak kertas aslinya. Penanganan hewan pengerat dengan memasang umpan racun yang diharapkan mengurangi populasi hewan pengerat yang merusak kertas serta penyemprotan racun serangga pada ruangan di gudang.

\section{Tahap Pemulihan}

Tahap keempat dalam kesiagaan menghadapi bencana yaitu tahap pemulihan mencakup kegiatan jangka panjang untuk memulihkan kembali sistem yang lumpuh atau terganggu selama bencana. Misalnya hilangnya database karena komputer hilang atau rusak. Untuk memperbaikinya dengan mengembalikan database dengan mengambil data melalui impor dari hasil backup data, sehingga database akan pulih seperti semula. Kegiatan pemulihan berupa pendataan kerusakan dan upaya pengadaan maupun penggantian koleksi yang rusak atau reproduksi koleksi digital ke tercetak.

Sebagaimana diketahui bahwa tujuan dan fungsi perpustakaan adalah mengumpulkan, menata, melestarikan dan menyediakan bahan pustaka dalam berbagai bentuk, meliputi semua bahan yang memuat atau merekam pengetahuan dan pikiran manusia. Dengan adanya kesiagaan terhadap bencana, di harapkan aspek kelestarian koleksi akan terjaga melalui berbagai kegiatan preservasi sehingga koleksi dapat didayagunakan dalam jangka waktu lama.

\section{E. KESIMPULAN}

Kesiapan dalam menghadapi bencana melalui tahapan kegiatan pencegahan, tanggapan, reaksi dan pemulihan. Pencegahan dengan mewajibkan pengunjung untuk mengisi buku kunjungan, memasang kamera CCTV, pemeriksaan perlindungan terhadap kebakaran berupa tabung pemadam portable, mengadakan sosialisasi kepada mahasiswa tentang tata penggunaan koleksi yang baik dan benar dalam forum Osmaru atau setiap hari Perpustakaan memberikan layanan pendidikan pemakai pada kelompok-kelompok kecil pemustaka. Tahap Tanggapan meliputi penyiapan SOP (Standart Operating Procesure) berupa urutan prioritas koleksi dalam penyelamatan ketika terjadi bencana berupa prosedur mutu, mengikut sertakan dalam berbagai pelatihan tentang preservasi, mengadakan kerjasama dengan pemadam kebakaran untuk simulai seandainya terjadi kebakaran, pusat arsip nasional untuk pelatihan preservasi. Tahap Reaksi Meliputi perbaikan jika tingkat ringan seperti penjilidan dan lain-lain, untuk buku yang hilang beberapa halaman dilakukan perbaikan penambahan isi yang hilang dengan fotokopi dari koleksi lain kemudian disatukan dan dijilid ulang. Namun jika kerusakan koleksi berat bisa dilaksanakan dengan alih media dengan scanning koleksi. Untuk penanganan koleksi yang basah, bagian preservasi mempunyai tempat pengeringan sistem dingin, menangani hewan pengerat dengan memasang umpan racun yang diharapkan mengurangi populasi hewan pengerat yang merusak kertas serta penyemprotan racun serangga pada ruangan di gudang. Tahap Pemulihan meliputi mengembalikan database dengan mengambil data melalui impor dari hasil backup data, sehingga database akan pulih seperti semula, pengadaan koleksi untuk menggantikan koleksi yang rusak atau reproduksi koleksi digital ke tercetak untuk menggantikan koleksi yang hilang atau rusak. 


\section{DAFTAR PUSTAKA}

A.A. Maidabino, A.N. Zainab, "Collection security management at university libraries: assessment of its implementation status", Malaysian Journal of Library \& Information Science, Vol.16, no.1, April 2011, hal. 16.

A. Ridwan Siregar, "Perluasan Peran Perpustakaan Perguruan Tinggi”, Jurnal Studi Perpustakaan dan Informasi, Juni 2008 Vol.4, No.1, hal .7.

Dureau, J.M. dan D.W.G. Clements (1990). Dasardasar pelestarian dan pengawetan bahanbahan pustaka. Jakarta : Perpustakaan Nasional. hal 13

- (1990). Dasar-dasar pelestarian dan pengawetan bahan-bahan pustaka. Jakarta : Perpustakaan Nasional. hal 18

- (1990). Dasar-dasar pelestarian dan pengawetan bahan-bahan pustaka. Jakarta : Perpustakaan Nasional. hal 35
Harvey, Ros.1993. Preservation in libraries: Principles, Strategies, and Practice for Librarias, London:Bowker-Saur hal 123

Matthews, G., \& Feather, J.. (2003). Disaster management for libraries and archives. Hampshire: Ashgate Publishing Co. hal 31

Peter Ingwersen. "The Role of Libraries and Librarians in Organising Digital Information", Libri Journal, 1999, vol 49, hal. 11-15.

P. Bryan Heidord, "The Emerging Role of Librariesin Data Curation and E-science", Journal of Library Administration, 2011 hal 663.

Tim Redaksi, Kamus Besar Bahasa Indonesia Pusat Bahasa, (Jakarta:Gramedia, 2012), hal.1297 